Published in final edited form as:

J Am Chem Soc. 2019 December 26; 141(51): 19973-19977. doi:10.1021/jacs.9b09900.

\title{
Multivalent Cation-Induced Actuation of DNA-Mediated Colloidal Superlattices
}

\author{
Devleena Samanta $^{\dagger, \|}$, Aysenur Iscen ${ }^{\ddagger}$, Christine R. Laramy ${ }^{\ddagger, \|}$, Sasha B. Ebrahimi ${ }^{\ddagger, \|}$, \\ Katherine E. Bujold ${ }^{\dagger, \|}$, George C. Schatz ${ }^{*},+\|$, Chad A. Mirkin ${ }^{*} \dagger, \|, \ddagger$ \\ †Department of Chemistry, Northwestern University, 2145 Sheridan Road, Evanston, Illinois \\ 60208, United States \\ "International Institute for Nanotechnology, Northwestern University, 2145 Sheridan Road, \\ Evanston, Illinois 60208, United States \\ ¥Department of Chemical and Biological Engineering, Northwestern University, 2145 Sheridan \\ Road, Evanston, Illinois 60208, United States
}

\begin{abstract}
Nanoparticles functionalized with DNA can assemble into ordered superlattices with defined crystal habits through programmable DNA "bonds". Here, we examine the interactions of multivalent cations with these DNA bonds as a chemical approach for actuating colloidal superlattices. Multivalent cations alter DNA structure on the molecular scale, enabling the DNA "bond length" to be reversibly altered between 17 and $3 \mathrm{~nm}$, ultimately leading to changes in the overall dimensions of the micrometer-sized superlattice. The identity, charge, and concentration of the cations each control the extent of actuation, with $\mathrm{Ni}^{2+}$ capable of inducing a remarkable $>65 \%$ reversible change in crystal volume. In addition, these cations can increase "bond strength", as evidenced by superlattice thermal stability enhancements of $>60^{\circ} \mathrm{C}$ relative to systems without multivalent cations. Molecular dynamics simulations provide insight into the conformational changes in DNA structure as the bond length approaches $3 \mathrm{~nm}$ and show that cations that screen the negative charge on the DNA backbone more effectively cause greater crystal contraction. Taken together, the use of multivalent cations represents a powerful strategy to alter superlattice structure and stability, which can impact diverse applications through dynamic control of material properties, including the optical, magnetic, and mechanical properties.
\end{abstract}

Nanoparticles functionalized with a dense shell of oligonucleotides can be analogized as programmable atom equivalents (PAEs), which assemble into complex structures through their oligonucleotide ligands that act as programmable "bonds". ${ }^{1-11}$ Importantly, unlike atomic systems such as ionic crystals, the PAE core (size, shape, composition) and the DNA

\footnotetext{
*Corresponding Authors: chadnano@northwestern.edu, g-schatz@northwestern.edu.

Supporting Information

The Supporting Information is available free of charge at https://pubs.acs.org/doi/10.1021/jacs.9b09900.

Experimental methods, additional discussions, and Figures S1-S28 (PDF)

Movie S1, contraction with Ni(II) (.mp4); Movie S2, contraction with CoHA (.mp4); and Movie S3, real-time superlattice contraction with $\mathrm{Ni}(\mathrm{II})$ (.avi) (ZIP)

The authors declare no competing financial interest.
} 
bond (sequence, length, strength, density) can be varied independently, to produce a rich and diverse phase-space of matter. ${ }^{11}$ The presence of DNA makes these structures responsive to stimuli. While some design elements (e.g., hairpins, ${ }^{12} \mathrm{pH}$-sensitive i-motifs, ${ }^{13}$ lightsensitive azo-benzene ${ }^{14}$ ) can be deliberately engineered into these structures to impart responsiveness, other strategies take advantage of the inherent sensitivity of DNA to certain stimuli (e.g., solvent exchange, ${ }^{15}$ humidity, ${ }^{16}$ osmotic pressure, ${ }^{17}$ ionic strength ${ }^{18}$ ). In the context of assembled PAEs, these stimuli allow one to dynamically alter the interparticle spacings postsynthetically, thus leading to a new class of tunable metamaterials.

Here, we present a chemical approach that enables dynamic control of DNA bonds with multivalent cations. Our experiments show that DNA bonds contract by $>80 \%$ in the presence of these ions and are restored upon their removal. Moreover, we are able to observe through simulations the change in molecular structure and free energy during this large contraction, a feat not possible with previous computational models. ${ }^{15}$

Multivalent cations are critical to structural changes associated with several biological phenomena including muscle actuation, electrical excitation of cells, and nerve signal propagation. ${ }^{19-21}$ In addition, it is well-known that the structure of free DNA in solution can be dramatically altered by these ions. ${ }^{22-28}$ For example, nuclear DNA exists in a highly condensed phase due to its interactions with histone proteins with multiple positive charges. 22 DNA condensation and precipitation are also observed with other biological polyamines such as spermine and spermidine as well as with inorganic amines such as cobalt hexamine chloride. ${ }^{23-25}$ In this light, we hypothesized that changes in DNA structure induced by multivalent cations could drive actuation of colloidal superlattices comprised of PAEs (Figure 1).

To test this hypothesis, we designed two sets of PAEs with identical nanoparticle cores (30 $\mathrm{nm}$ diameter spherical gold nanoparticles) and complementary DNA such that their interactions result in a body-centered cubic (bcc) lattice upon slow cooling. Indeed, the nanoparticles formed singlecrystalline bcc superlattices with rhombic dodecahedron crystal habits, as evidenced by small-angle X-ray scattering (SAXS) and electron microscopy (Figures 2 and 3).

To study the effect of multivalent cations on these superlattices, we initially chose the trivalent cation cobalt hexamine, $\left[\mathrm{Co}\left(\mathrm{NH}_{3}\right)_{6}\right]^{3+}$, as a model cation guided by the following considerations: (i) typically, $3+$ or higher charges are required to condense free DNA in solution and (ii) the interaction of $\left[\mathrm{Co}\left(\mathrm{NH}_{3}\right)_{6}\right]^{3+}$ with free DNA has been extensively studied and it is well-known to primarily associate with the DNA backbone causing condensation. 29-32 Interestingly, we observed a gradual increase in the $q$ values in the position of the peaks in the SAXS patterns as increasing concentrations of $\left[\mathrm{Co}\left(\mathrm{NH}_{3}\right)_{6}\right] \mathrm{Cl}_{3}$ were added to the superlattices dispersed in $0.25 \mathrm{M} \mathrm{NaCl}$. From the SAXS data, we calculated the apparent DNA "bond length" $\left(L_{\mathrm{DNA}}\right)$ which corresponds to the surface-to-surface distance between the particles. As shown in Figure 2, $L_{\mathrm{DNA}}$ decreases monotonically from 17 to $7 \mathrm{~nm}$ ( $60 \%$ change) as the concentration of $\left[\mathrm{Co}\left(\mathrm{NH}_{3}\right)_{6}\right]^{3+}$ gradually increases from 0 to $50 \mathrm{mM}$. Moreover, this contraction is reversible; dilution to a lower concentration of $\left[\mathrm{Co}\left(\mathrm{NH}_{3}\right)_{6}\right]^{3+}$ restores the original bond length (Figure 2). Importantly, superlattices retain their lattice 
symmetry and crystal habit throughout the actuation process (Figures 2 and 3), which suggests that the DNA remains hybridized. Similar results are obtained when $20 \mathrm{~nm}$ gold nanoparticles are used as the PAE cores or longer DNA is used (Figures S8 and S9). Variable-temperature absorbance spectroscopy and variable-temperature in situ SAXS measurements show that the melting temperature of the superlattices increases with increasing ionic strength; superlattices are stable against dissociation up to at least $95{ }^{\circ} \mathrm{C}$ at $12.5 \mathrm{mM}\left[\mathrm{Co}\left(\mathrm{NH}_{3}\right)_{6}\right]^{3+}$ (Figure $\mathrm{S} 6$ ). These results demonstrate that multivalent cations can be used to increase DNA "bond strength" and superlattice stability.

Due to the limited aqueous solubility of $\left[\mathrm{Co}\left(\mathrm{NH}_{3}\right)_{6}\right] \mathrm{Cl}_{3}$, we explored if other cations with higher solubility could be used to induce greater actuation. We studied the effect of cation charge and concentration on superlattice contraction (Figure 4A). To control for possible counterion effects, only chloride salts were used. For $50 \mathrm{mM}$ added salt, unlike the significant $\sim 60 \%$ bond contraction obtained with $\left[\mathrm{Co}\left(\mathrm{NH}_{3}\right)_{6}\right]^{3+}$, we observed negligible changes with $\mathrm{Na}^{+}(<0.4 \%)$ and moderate changes with $\mathrm{Mg}^{2+}(\sim 15 \%)$. Moreover, only $\sim 14$ and $\sim 31 \%$ bond contractions were observed with $2 \mathrm{M} \mathrm{Na}^{+}$and $\mathrm{Mg}^{2+}$, respectively. These results suggest that the charge of the cations has a strong influence on the extent of actuation and that $\mathrm{Na}^{+}$and $\mathrm{Mg}^{2+}$ have a significantly lower ability to screen the negative charges on DNA compared to $\left[\mathrm{Co}\left(\mathrm{NH}_{3}\right)_{6}\right]^{3+}$. Our results are consistent with the observation that $\mathrm{Na}^{+}$ and $\mathrm{Mg}^{2+}$ do not condense free DNA in solution. ${ }^{25}$

To determine if the observed effects are functions of charge and ionic strength alone, we sought to explore how a different cation with the same charge would interact with the DNA. As a direct comparison to $\mathrm{Mg}^{2+}$, we chose $\mathrm{Ni}^{2+}$, a transition metal ion with similar ionic radius. Remarkably, $50 \mathrm{mM} \mathrm{Ni}^{2+}$ induces a $50 \%$ bond contraction, and $2 \mathrm{M} \mathrm{Ni}^{2+}$ allows $>80 \%$ change (Figure $2 \mathrm{C}, \mathrm{D}$ ). The $L_{\mathrm{DNA}}$ is reduced to merely $\sim 3 \mathrm{~nm}$ at this concentration, and the crystal volume changes by $>65 \%$. As before, the actuation with $\mathrm{Ni}^{2+}$ is reversible. Using confocal microscopy, we could observe the crystal contraction in real time and found that it occurs at sub-second time scales and is complete within $2 \mathrm{~s}$ (Figures 4B, S11-S13, and Movie S3). These results show that multivalent cations can be used to effect large, fast, and reversible volume changes in colloidal crystals, thereby dynamically modulating their properties.

The dramatic differences in actuation observed with $\mathrm{Mg}^{2+}$ and $\mathrm{Ni}^{2+}$ show that the extent of lattice contraction is highly dependent on the nature of the salt in solution. Furthermore, addition of multivalent cations can lead to contraction ratios that can be achieved by very few methods. ${ }^{15-17}$ However, experimentally probing the mechanism of actuation and the structure of DNA in the condensed state within the superlattice is exceedingly challenging. Therefore, we performed full atomistic molecular dynamics (MD) simulations to elucidate the molecular mechanism of contraction and understand the origin of the differences observed with $\mathrm{Na}^{+}, \mathrm{Mg}^{2+}$, and $\mathrm{Ni}^{2+}$.

Using steered MD and umbrella sampling methods, we explored the potential of mean force (PMF), which is the change in free energy relative to the extended DNA bond length, as a function of interparticle distance (Figure 5) for selected concentrations of several ions. Since our model does not account for dispersion interactions between the spherical nanoparticles, 
we estimated these forces in our system based on the known Hamaker constants. These forces introduce an additional driving term that stabilizes the compressed structures (SI section 4.10.3, Figure S26) but are not included in Figure 5. The simulations suggest that in $250 \mathrm{mM} \mathrm{Na}^{+}$without multivalent cations, there are two interparticle distances, 14.5 and 7.2 $\mathrm{nm}$, at which the superlattice is most stable. However, an energy barrier of $\sim 20 \mathrm{kcal} / \mathrm{mol}$ between these two regions prevents DNA contraction in the absence of a driving force. Upon addition of $2 \mathrm{M} \mathrm{Na}^{+}$, the PMF minimum remains at $14.5 \mathrm{~nm}$, but shifts to $13.3 \mathrm{~nm}$ when $2 \mathrm{M}$ $\mathrm{Mg}^{2+}$ is added. The shift to lower interparticle distances agrees qualitatively with the experimentally observed shifts from 17 to 14.8 and $11.8 \mathrm{~nm}$, respectively. Significantly, when $2 \mathrm{M} \mathrm{Ni}^{2+}$ is added, the energy barrier is reduced, and a PMF minimum appears at 4.2 $\mathrm{nm}$, in close agreement with the experimentally observed interparticle distance of $3.2 \mathrm{~nm}$. It is interesting to note that this distance is roughly twice the diameter of doublestranded DNA. Inspection of the structures (Figure 5A-D) at the experimentally observed DNA bond lengths reveals that the DNA strands between the gold surfaces remain hybridized and the DNA bends to accommodate the change in the distance. At the shortest distance $(3.2 \mathrm{~nm})$, the DNA chains form C-shaped loops pressed against the gold surfaces without dehybridizing (Movie S1).

To gain further insight into how different salts influence contraction, we looked at changes in the local environment of the DNA. Whether a cation interacts directly with DNA is based on the total charge and solvation properties of the cation in water. As the net charge on the cation $\left(\mathrm{Na}^{+}<\mathrm{Mg}^{2+}, \mathrm{Ni}^{2+}<\left[\mathrm{Co}\left(\mathrm{NH}_{3}\right)_{6}\right]^{3+}\right)$ is increased, a stronger interaction between the cation and the DNA backbone is observed (Figures S20 and S23E). However, although the charges on $\mathrm{Mg}^{2+}$ and $\mathrm{Ni}^{2+}$ are equal, $\mathrm{Ni}^{2+}$ shows significantly more binding to DNA (Figure 5F). Moreover, $\mathrm{Ni}^{2+}$ is less solvated compared to $\mathrm{Mg}^{2+}$ (Figures 5G and S21C), indicating that it is more likely to exchange its water ligands and interact directly with the DNA chains. The increased binding of $\mathrm{Ni}^{2+}$ screens the negative charges on the DNA backbones more effectively, reduces repulsion between the chains, and allows the DNA to adopt a bent conformation. Based on these results, we hypothesized that the binding affinity of different metals to DNA acts as a driving force for the superlattice contraction and determines the extent of it.

To verify our hypothesis, we studied the interactions of a series of different monovalent and divalent metal ions $\left(\mathrm{Na}^{+}, \mathrm{K}^{+}, \mathrm{NH}_{4}^{+}, \mathrm{Mg}^{2+}, \mathrm{Ca}^{2+}, \mathrm{Ni}^{2+}, \mathrm{Co}^{2+}, \mathrm{Mn}^{2+}, \mathrm{Cu}^{2+}\right)$ with the superlattice. We performed electrophoretic mobility shift assays (EMSAs) to qualitatively estimate the relative binding affinities of these ions. The extent of migration of DNA in the presence of a cation is reflective of the binding affinity; stronger binding metals retard DNA migration more. Relative binding affinities determined by EMSA are qualitatively consistent with previous experimental reports i.e., $\mathrm{Cu}^{2+}>\mathrm{Mn}^{2+}, \mathrm{Co}^{2+}, \mathrm{Ni}^{2+}>\mathrm{Ca}^{2+}, \mathrm{Mg}^{2+}>\mathrm{Na}^{+}, \mathrm{K}^{+}$, $\mathrm{NH}_{4}+3,34$ and supported by MD simulations on free DNA strands in aqueous salt solutions (Figures S27 and S28). When superlattices are treated with $50 \mathrm{mM}$ of these ions, the contractions observed are correlated with these binding affinity patterns (Figure S10), thus supporting our hypothesis.

In summary, we have developed a chemical approach to reversibly contract and expand colloidal crystals by $>65 \%$ in volume using multivalent cations. Due to the monotonic 
dependence of the actuation on cation concentration, this strategy represents the most precise method to dynamically control interparticle distances. Such an approach could be potentially used in distance-dependent studies of optical, magnetic, and mechanical properties of colloidal superlattices. Moreover, it will provide access to responsive biomaterials (by swapping out core materials), tunable metamaterials, and, through redoxsensitive cations, electrochemically controlled actuators.

\section{Supplementary Material}

Refer to Web version on PubMed Central for supplementary material.

\section{ACKNOWLEDGMENTS}

This material is based upon work supported by the Air Force Office of Scientific Research award FA9550-17-1-0348 (PAE synthesis and assembly); the Vannevar Bush Faculty Fellowship program sponsored by the Basic Research Office of the Assistant Secretary of Defense for Research and Engineering and funded by the Office of Naval Research through grant N00014-15-1-0043 (oligonucleotide analyses); the Center for Bio-Inspired Energy Science, an Energy Frontier Research Center funded by the U.S. Department of Energy, Office of Science, Basic Energy Sciences under award DE-SC0000989 (PAE actuation and computational studies); and the National Cancer Institute of the National Institutes of Health under award U54CA199091 (imaging and microscopy). This material was also sponsored by the Air Force Research Laboratory under agreement FA8650-15-2-5518 (imaging and microscopy). This work made use of the EPIC facility of Northwestern University's NUANCE Center, which has received support from the Soft and Hybrid Nanotechnology Experimental (SHyNE) Resource (NSF ECCS-1542205). SAXS experiments were performed at the Dupont-Northwestern-Dow Collaborative Access Team beamline at the Advanced Photon Source (APS) in Argonne National Laboratory, which receives support from the U.S. Department of Energy (DE-AC02-06CH11357). C.R.L. was supported through a Graduate Research Fellowship from the National Science Foundation. S.B.E. was supported in part by the Chicago Cancer Baseball Charities and the H Foundation at the Lurie Cancer Center of Northwestern University. K.E.B. was supported by a Banting Postdoctoral Fellowship from the Government of Canada. We are grateful to Dr. H. Lin for helpful discussions and Z. Urbach for assistance in collecting selected SAXS data.

\section{REFERENCES}

(1). Alivisatos AP; Johnsson KP; Peng X; Wilson TE; Loweth CJ; Bruchez MP; Schultz PG Organization of "Nanocrystal Molecules" Using DNA. Nature 1996, 382, 609-611. [PubMed: 8757130]

(2). Nykypanchuk D; Maye MM; Van Der Lelie D; Gang O DNA-Guided Crystallization of Colloidal Nanoparticles. Nature 2008, 451, 549-552. [PubMed: 18235496]

(3). Macfarlane RJ; Lee B; Jones MR; Harris N; Schatz GC; Mirkin CA Nanoparticle Superlattice Engineering with DNA. Science 2011, 334, 204-208. [PubMed: 21998382]

(4). Jones MR; Seeman NC; Mirkin CA Programmable Materials and the Nature of the DNA Bond. Science 2015, 347, 1260901. [PubMed: 25700524]

(5). Mirkin CA; Letsinger RL; Mucic RC; Storhoff JJ A DNA-Based Method for Rationally Assembling Nanoparticles into Macroscopic Materials. Nature 1996, 382, 607-609. [PubMed: 8757129]

(6). Park SY; Lytton-Jean AKR; Lee B; Weigand S; Schatz GC; Mirkin CA DNA-Programmable Nanoparticle Crystallization. Nature 2008, 451, 553-556. [PubMed: 18235497]

(7). Zhang C; MacFarlane RJ; Young KL; Choi CHJ; Hao L; Auyeung E; Liu G; Zhou X; Mirkin CA A General Approach to DNA-Programmable Atom Equivalents. Nat. Mater 2013, 12, 741-746. [PubMed: 23685863]

(8). Tian Y; Zhang Y; Wang T; Xin HL; Li H; Gang O Lattice Engineering through Nanoparticle-DNA Frameworks. Nat. Mater 2016, 15, 654-661. [PubMed: 26901516]

(9). Auyeung E; Li TING; Senesi AJ; Schmucker AL; Pals BC; De La Cruz MO; Mirkin CA DNAMediated Nanoparticle Crystallization into Wulff Polyhedra. Nature 2014, 505, 73-77. [PubMed: 24284632] 
(10). Macfarlane RJ; Lee B; Hill HD; Senesi AJ; Seifert S; Mirkin CA Assembly and Organization Processes in DNA-Directed Colloidal Crystallization. Proc. Natl. Acad. Sci. U. S. A 2009, 106, 10493-10498. [PubMed: 19549828]

(11). Laramy CR; O’Brien MN; Mirkin CA Crystal Engineering with DNA. Nature Reviews Materials. 2019, 4, 201-224.

(12). Kim Y; Macfarlane RJ; Mirkin CA Dynamically Interchangeable Nanoparticle Superlattices through the Use of Nucleic Acid-Based Allosteric Effectors. J. Am. Chem. Soc 2013, 135, 10342-10345. [PubMed: 23822216]

(13). Zhu J; Kim Y; Lin H; Wang S; Mirkin CA pH-Responsive Nanoparticle Superlattices with Tunable DNA Bonds. J. Am. Chem. Soc 2018, 140, 5061-5064. [PubMed: 29624374]

(14). Yan Y; Chen JIL; Ginger DS Photoswitchable Oligonucleotide-Modified Gold Nanoparticles: Controlling Hybridization Stringency with Photon Dose. Nano Lett. 2012, 12, 2530-2536. [PubMed: 22493996]

(15). Mason JA; Laramy CR; Lai CT; O’Brien MN; Lin QY; Dravid VP; Schatz GC; Mirkin CA Contraction and Expansion of Stimuli-Responsive DNA Bonds in Flexible Colloidal Crystals. J. Am. Chem. Soc 2016, 138, 8722-8725. [PubMed: 27402303]

(16). Radha B; Senesi AJ; O’Brien MN; Wang MX; Auyeung E; Lee B; Mirkin CA Reconstitutable Nanoparticle Superlattices. Nano Lett. 2014, 14, 2162-2167. [PubMed: 24641553]

(17). Srivastava S; Nykypanchuk D; Maye MM; Tkachenko AV; Gang O Super-Compressible DNA Nanoparticle Lattices. Soft Matter 2013, 9, 10452-10457.

(18). Xiong H; Sfeir MY; Gang O Assembly, Structure and Optical Response of Three-Dimensional Dynamically Tunable Multicomponent Superlattices. Nano Lett. 2010, 10 (11), 4456-4462. [PubMed: 20879781]

(19). Szent-Györgyi AG Calcium Regulation of Muscle Contraction. Biophys. J 1975, 15, 707-723. [PubMed: 806311]

(20). Heilbrunn LV; Wiercinski FJ The Action of Various Cations of Muscle Protoplasm. J. Cell. Comp. Physiol 1947, 29, 15-32. [PubMed: 20285919]

(21). Katz B; Miledi R The Effect of Calcium on Acetylcholine Release from Motor Nerve Terminals. Proc. R. Soc. London. Ser. B. Biol. Sci 1965, 161, 496-503. [PubMed: 14278410]

(22). Richmond TJ; Davey CA The Structure of DNA in the Nucleosome Core. Nature 2003, 423, 145-150. [PubMed: 12736678]

(23). Baumann CG; Smith SB; Bloomfield VA; Bustamante C Ionic Effects on the Elasticity of Single DNA Molecules. Proc. Natl. Acad. Sci. U. S. A 1997, 94, 6185-6190. [PubMed: 9177192]

(24). Besteman K; Van Eijk K; Lemay SG Charge Inversion Accompanies DNA Condensation by Multivalent Ions. Nat. Phys 2007, 3, 641-644.

(25). Bloomfield VA DNA Condensation. Curr. Opin. Struct. Biol 1996, 6, 334-341. [PubMed: 8804837]

(26). Zhou W; Saran R; Liu J Metal Sensing by DNA. Chem. Rev 2017, 117, 8272-8325. [PubMed: 28598605]

(27). Samanta D; Ebrahimi SB; Mirkin CA Nucleic-Acid Structures as Intracellular Probes for Live Cells. Adv. Mater 2019, 1901743.

(28). Ebrahimi SB; Samanta D; Cheng HF; Nathan LI; Mirkin CA Forced Intercalation (FIT)Aptamers. J. Am. Chem. Soc 2019, 141, 13744-13748. [PubMed: 31441661]

(29). Deng H; Bloomfield VA Structural Effects of Cobalt-Amine Compounds on DNA Condensation. Biophys. J 1999, 77, 1556-1561. [PubMed: 10465766]

(30). Bloomfield VA Condensation of DNA by Multivalent Cations: Considerations on Mechanism. Biopolymers 1991, 31, 1471-1481. [PubMed: 1814499]

(31). Widom J; Baldwin RL Cation-Induced Toroidal Condensation of DNA. Studies with Co3+ (NH3)6. J. Mol. Biol1980, 144, 431-453. [PubMed: 6454789]

(32). Plum GE; Arscott PG; Bloomfield VA Condensation of DNA by Trivalent Cations. 2. Effects of Cation Structure. Biopolymers 1990, 30, 631-643. [PubMed: 2265234]

(33). Shamsi MH; Kraatz HB Interactions of Metal Ions with DNA and Some Applications. J. Inorg. Organomet. Polym. Mater 2013, 23, 4-23. 
(34). Hackl EV; Kornilova SV; Blagoi YP DNA Structural Transitions Induced by Divalent Metal Ions in Aqueous Solutions. Int. J. Biol. Macromol 2005, 35, 175-191. [PubMed: 15811473] 

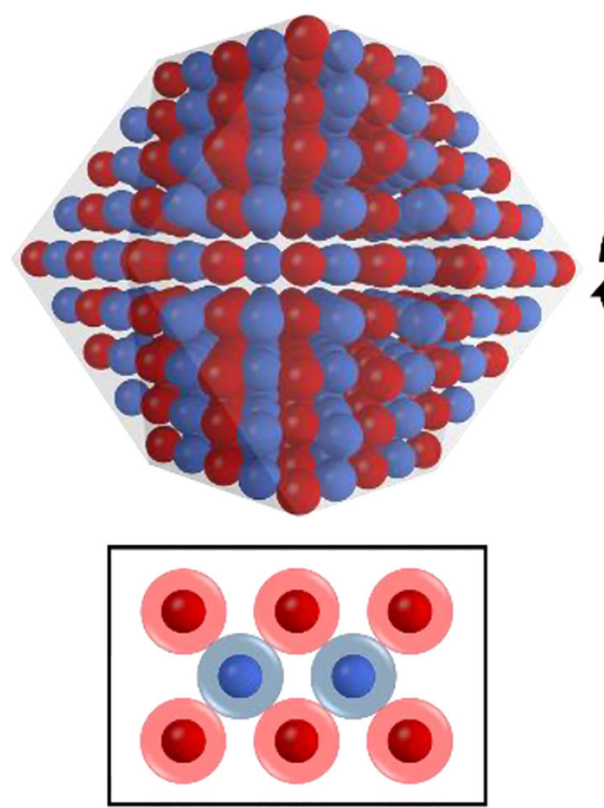

$\mathrm{M}^{\mathrm{n}+}$ Multivalent cations $\bigcirc \mathrm{NP}$ core
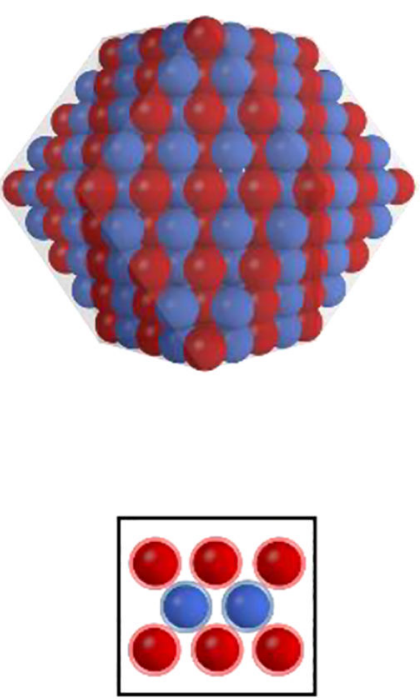

Figure 1.

Scheme shows reversible actuation of DNA-mediated colloidal superlattices using multivalent cations. The DNA "bonds" contract in the presence of multivalent cations and are restored upon their removal. 
A

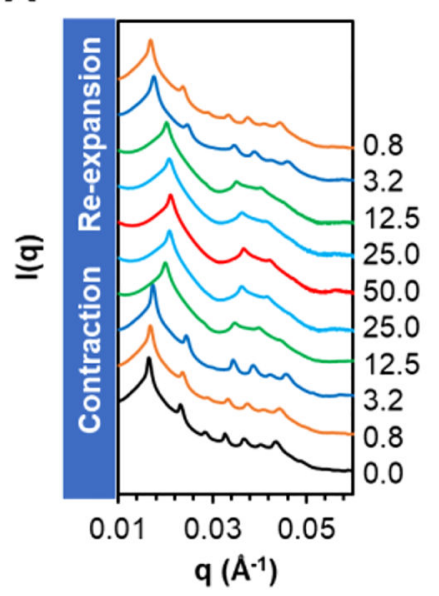

C

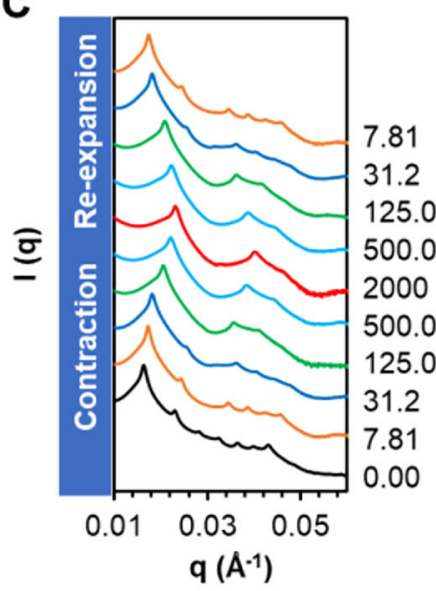

B
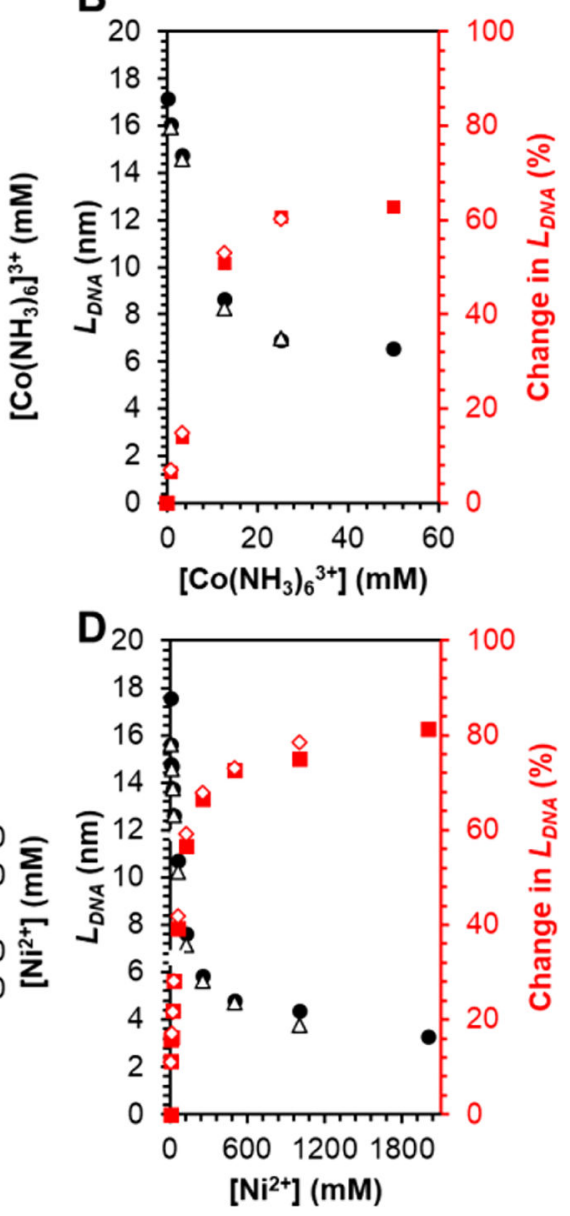

Figure 2.

Superlattice actuation with $\left[\mathrm{Co}\left(\mathrm{NH}_{3}\right)_{6}\right] \mathrm{Cl}_{3}$ and $\mathrm{NiCl}_{2}$. (A,C). SAXS patterns show that the actuation is reversible. (B, D). The DNA bond length decreases with increasing concentration of the cations. Solid and hollow points correspond to contraction and expansion, respectively. 

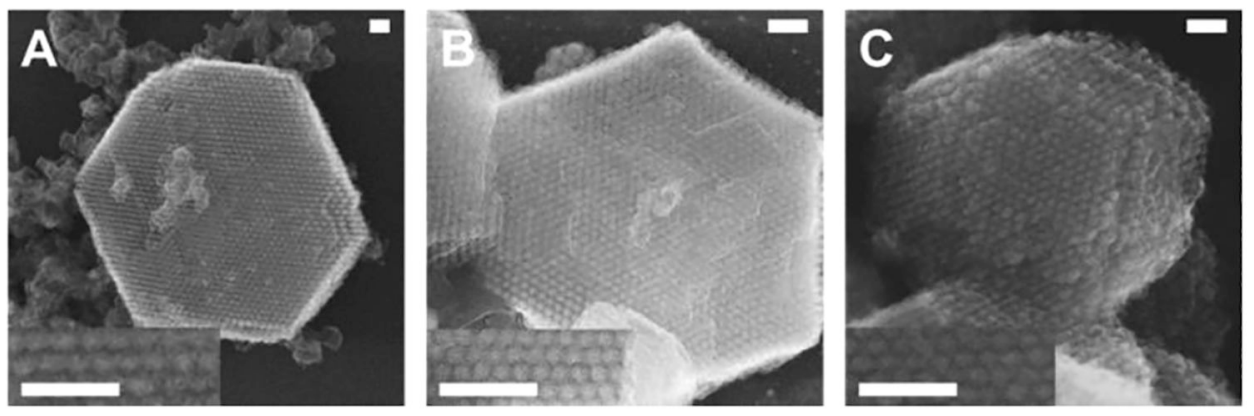

Figure 3.

Scanning electron micrographs of superlattices with (A) no added multivalent cations, (B) $50 \mathrm{mM}$ added $\left[\mathrm{Co}\left(\mathrm{NH}_{3}\right)_{6}\right]^{3+}$, and (C) $2 \mathrm{M}$ added $\mathrm{Ni}^{2+}$. Scale bars: $125 \mathrm{~nm}$. 
A

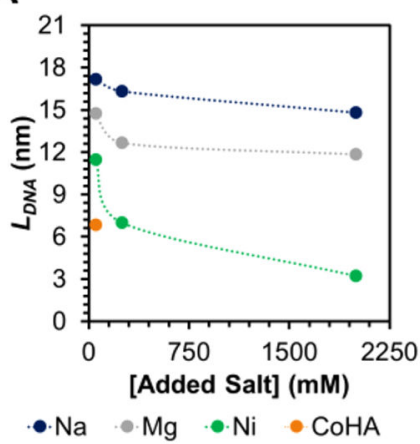

B

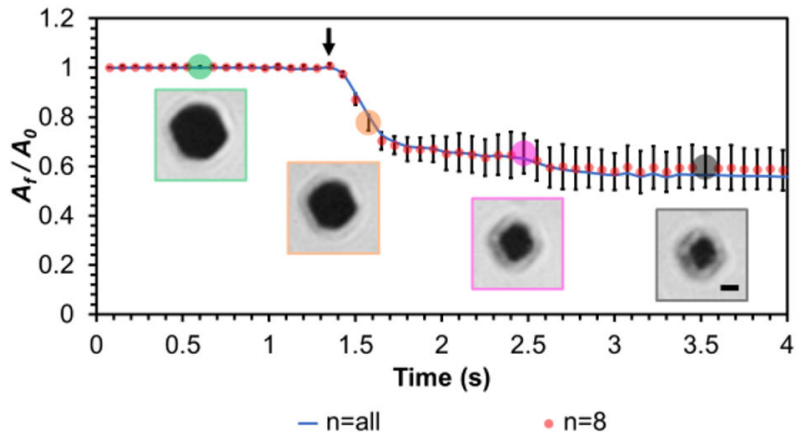

Figure 4.

(A) Superlattice contraction with different cations. CoHA $=\left[\mathrm{Co}\left(\mathrm{NH}_{3}\right)_{6}\right]^{3+}$ (B) Time scale of superlattice contraction in the presence of excess $\mathrm{Ni}^{2+}$. Blue line corresponds to the ratio of the final $\left(A_{f}\right)$ and initial $\left(A_{0}\right)$ areas occupied by all the crystals in the field of view at different points in time. Red dots designate the same for the average of eight individual crystals. Error bars denote one standard deviation, arrow indicates the addition of $\mathrm{Ni}^{2+}$, and all images showing the contracting crystal are brightfield. Scale bar represents $1 \mu \mathrm{m}$. 


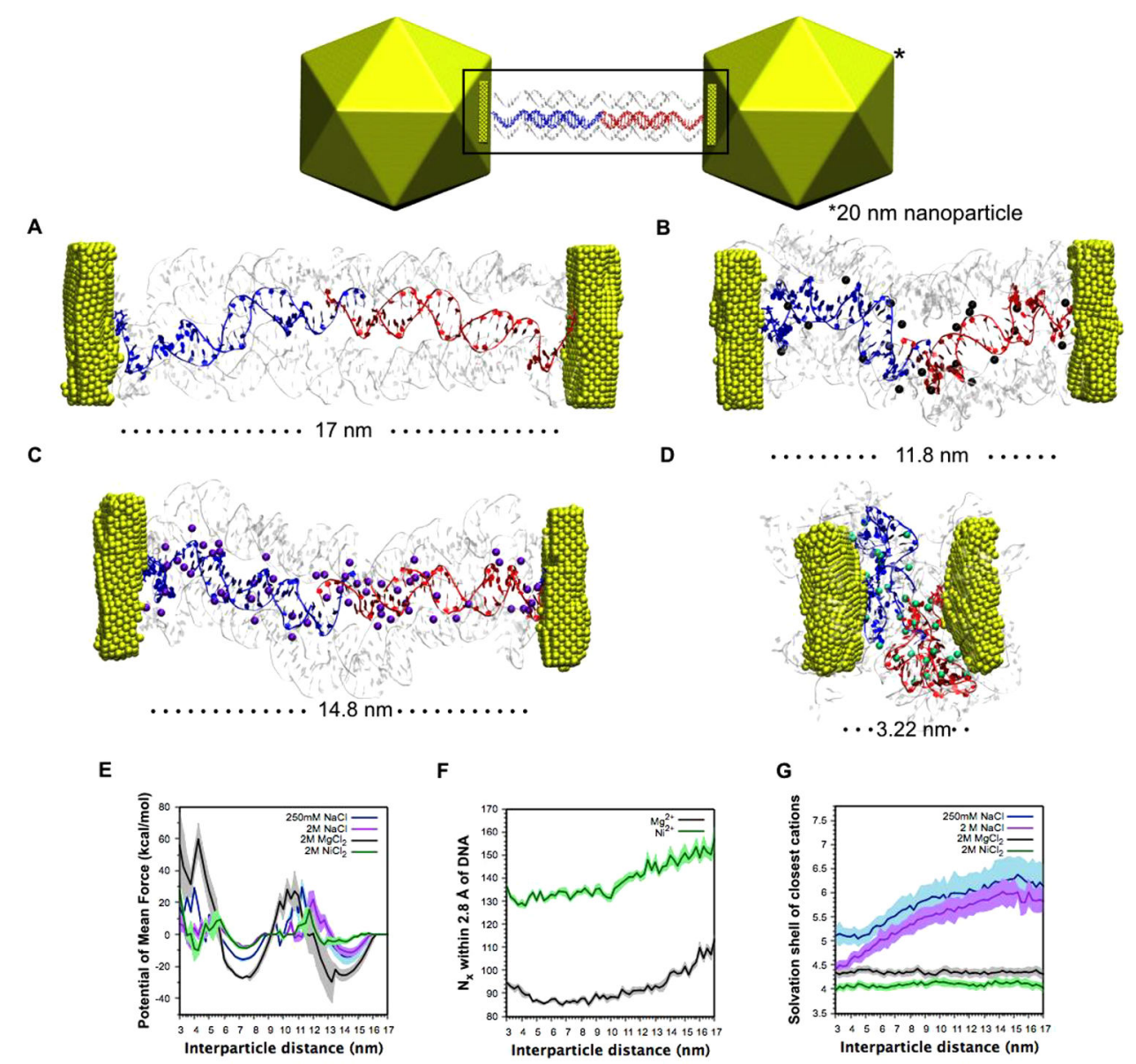

Figure 5.

(A-D) Snapshots from MD simulations corresponding to the experimental nanolattice contraction for (A) $250 \mathrm{mM} \mathrm{NaCl}$ (control), (B) control + $2 \mathrm{M} \mathrm{MgCl}_{2}$, (C) control + $2 \mathrm{M}$ $\mathrm{NaCl}$, and (D) control $+2 \mathrm{M} \mathrm{NiCl}_{2}$. Gold surfaces are shown in yellow. Central DNA is shown in blue (A strand) and red (B strand). For structures in (B-D) only the $\mathrm{Na}^{+}$(purple), $\mathrm{Ni}^{2+}$ (green), and $\mathrm{Mg}^{2+}$ (black) within $2.8 \AA$ of the DNA are shown. The rest of the $\mathrm{Na}^{+}$and $\mathrm{Cl}^{-}$ions and water are omitted for clarity. (E) Potential of mean force for contraction of the DNA nanolattice. Solid lines are average values calculated from three independent umbrella sampling simulations and the shaded region is the standard error of mean. (F) Average number of multivalent cations within $2.8 \AA$ of the DNA. (G) Average number of water molecules in the $1^{\text {st }}$ solvation shell of cations closest $(<2.8 \AA)$ to the DNA. 